\title{
IKBKAP/ELPI gene mutations: mechanisms of familial dysautonomia and gene-targeting therapies
}

This article was published in the following Dove Press journal: The Application of Clinical Genetics

\section{Berish Y Rubin \\ Sylvia L Anderson}

Department of Biological Sciences, Fordham University, Bronx, NY, USA

\begin{abstract}
The successful completion of the Human Genome Project led to the discovery of the molecular basis of thousands of genetic disorders. The identification of the mutations that cause familial dysautonomia (FD), an autosomal recessive disorder that impacts sensory and autonomic neurons, was aided by the release of the human DNA sequence. The identification and characterization of the genetic cause of FD have changed the natural history of this disease. Genetic testing programs, which were established shortly after the disease-causing mutations were identified, have almost completely eliminated the birth of children with this disorder. Characterization of the principal disease-causing mutation has led to the development of therapeutic modalities that ameliorate its effect, while the development of mouse models that recapitulate the impact of the mutation has allowed for the in-depth characterization of its impact on neuronal development and survival. The intense research focus on this disorder, while clearly benefiting the FD patient population, also serves as a model for the positive impact focused research efforts can have on the future of other genetic diseases. Here, we present the research advances and scientific breakthroughs that have changed and will continue to change the natural history of this centuries-old genetic disease.
\end{abstract}

Keywords: HSAN, splicing, MAO, tocotrienol, EGCG, Ashkenazi

\section{Introduction}

Familial dysautonomia (FD, OMIM \#223900), also known as Riley-Day syndrome, is an autosomal recessive congenital neuropathy that affects the development and survival of sensory and autonomic neurons. The identification and characterization of the FD-causing mutations in the ELPI (formerly known as IKBKAP) gene have enabled the rapid elucidation of the cellular, molecular and physiological action of this gene product and the role it plays in the pathophysiology of FD. The observed incomplete penetrance of the most common FD-causing mutation, which allows for the production of some functional gene product, has heralded a new era in the development of novel therapeutics that target the increased production of the functional gene product. The clinical use of several of these newly identified therapeutics has already demonstrated their ability to ameliorate the life-threatening symptoms of this disorder and will likely increase the long-term survival of this patient population. The rapid translation of the mutation discovery into the identification of novel targeted therapies represents a model for the development of new therapies for other disease-causing mutations.

\section{The FD phenotype}

The compromised development and survival of sensory, sympathetic and some parasympathetic neurons are hallmark symptoms of $\mathrm{FD}^{1,2}$ and it is based on these 
deficits that FD is characterized as a hereditary sensory and autonomic neuropathy (HSAN). Neuronal deficits have also recently been detected in the central nervous system of these patients. ${ }^{3,4}$ Examination of the neuronal development and deficits in individuals with FD have revealed: 1) diminished numbers of myelinated and non-myelinated axons in the sural nerve ${ }^{5,6} ; 2$ ) diminished neuronal presence in dorsal root ganglia in young patients and the progressive loss of neurons with age $^{7} ; 3$ ) depletion of axons in the spinal cord ${ }^{8}$; 4) a reduced volume of the superior cervical ganglia with a concomitant decrease in the number of neurons $\left.{ }^{8} ; 5\right)$ diminished presence of nerve fibers in the epidermis, subepidermal neural plexus and the deep epidermis $\left.{ }^{9} ; 6\right)$ decreased cardiac sympathetic innervation ${ }^{10}$; 7) reduced sympathetic innervation of peripheral blood vessels ${ }^{11} ; 8$ ) delayed and diminished brain stem reflexes, ${ }^{4}$ and 9) progressive optic nerve degeneration. ${ }^{12}$ Due to the various neuronal deficits, individuals with FD typically exhibit a reduced sensitivity to pain and temperature, difficulty swallowing, decreased or absent deep tendon reflexes, an ataxic gait, cardiovascular instability, defective lacrimation and gastrointestinal dysfunction. ${ }^{13}$ Additional manifestations of FD include: the reduced presence of fungiform papillae on the tongue, orthostatic hypotension, spinal deformities (scoliosis/kyphoscoliosis/kyphosis), dysautonomic crises and frequent aspiration pneumonias. ${ }^{13,14}$ During dysautonomic crisis, FD patients experience uncontrollable bouts of nausea, retching, vomiting, sialorrhea, erythematous skin rashes and hyperhidrosis, which are accompanied by hypertension and tachycardia. ${ }^{13,15}$ These crises can occur following emotional or physiologic stresses that trigger the release of catecholamines ${ }^{13,15,16}$ and in response to tyramine ingestion. ${ }^{17,18}$ Aspiration pneumonias are common in these patients and they typically occur as the result of either misdirected swallowing or the inhaling of stomach contents during dysautonomic crises. ${ }^{19}$ Aspiration pneumonias are a leading cause of death for this patient population. ${ }^{14}$

\section{The FD genotype}

FD is a member of a genetically and clinically heterogeneous group of HSANs and is classified as HSAN type III. FD is almost exclusively confined to individuals of Ashkenazi Jewish (AJ) descent and is the result of the inheritance of mutations in the ELP1 gene. ${ }^{20,21}$ Greater than $99 \%$ of individuals with FD are homozygous for a $\mathrm{T} \rightarrow \mathrm{C}$ transition at position 6 of the 5' (donor) splice site of intron 20 of the ELP1 gene (termed IVS20+6T $>$ C). This mutation, which is termed the "major" mutation because of its prevalence, compromises the base pairing of the U1 small nuclear ribonucleic protein to the intron 20 donor splice site, ${ }^{22}$ resulting in the skipping of the exon 20-encoded sequence. The mis-splicing of this transcript introduces a frameshift in the transcript and the translation of this mRNA generates a truncated $79 \mathrm{kDa}$ protein. ${ }^{20}$ The IVS20+6T $>C$ mutation is incompletely penetrant, allowing for the production of some full-length transcript. A second rare (termed "minor") disease-causing mutation present in the AJ population is a $\mathrm{G} \rightarrow \mathrm{C}$ transversion in exon 19 (c. $2087 \mathrm{G}>\mathrm{C}$ ) of the reported $\mathrm{I} \kappa \mathrm{B}$ kinase complex-associated protein (IKAP) cDNA that results in an arginine to proline substitution of amino acid 696 (p.Arg696Pro). ${ }^{20,21}$ This amino acid change disrupts a consensus serine/threonine kinase phosphorylation site (RIVT $\rightarrow$ pIVT), resulting in reduced phosphorylation at this site. ${ }^{20}$ The heterozygous inheritance of the IVS20+6T $>$ C and p.Arg696Pro mutations results in the typical FD phenotype. To date, no individuals have been identified who are homozygous for the p.Arg696Pro mutation. A third FD-causing mutation, and the first non-Jewish FDcausing mutation, was identified in a patient who inherited an IVS20+6T $>\mathrm{C}$ bearing allele from his $\mathrm{AJ}$ father and a proline to leucine missense mutation in exon 26 (p.Pro914Leu) from his non-Jewish mother. ${ }^{23}$ This patient exhibits the typical symptoms of this disease. A second non-Jewish disease-causing mutation has been identified in 2 children who inherited a single base insertion in exon 11 of the ELP1 gene from their non-Jewish father and the IVS20+6T $>C$ bearing allele from their AJ mother. The single base insertion in exon 11 generates a frameshift and the encoded protein lacks the amino acids encoded by exon 12 through 37 . The children who inherited both of these mutations exhibited severe neurological deficits and died before the age of 2 months (Anderson et al, manuscript in preparation).

Based on the birth incidence of FD in the AJ population, the carrier frequency of the defective gene was predicted to be $\sim 1$ in $30 .{ }^{24}$ Genotype screening for the FD-causing mutations performed on 3,246 non-selected healthy individuals of AJ descent demonstrated a carrier frequency of 1 in 30 for the IVS20+6T $>$ C mutation and 1 in 1,623 for the p.Arg696Pro mutation. ${ }^{25}$ Mutation screening performed on a small number of individuals of AJ descent suggested a higher carrier frequency among individuals of Polish ancestry. ${ }^{26}$ The most robust data on the carrier frequency of these 2 mutations comes from the Dor Yeshorim, Committee for Prevention of Jewish Genetic Diseases, screening program ${ }^{27}$ that has, to date, performed genetic testing for this disease on nearly 300,000 individuals of AJ descent. This program reports a carrier frequency of 1 in 27.5 for the IVS20+6T $>$ C mutation and 1 in 1,897 for the p.Arg696Pro mutation (Rabbi J Ekstein, 
Dor Yeshorim Executive Director, email communication, September, 2017). While the FD mutation clearly originated in the AJ population, ${ }^{28}$ genetic testing of $\sim 18,000$ Jewish individuals who identified themselves as being of pure Sephardic lineage revealed a carrier frequency of 1 in 3,031 for the IVS20+6T $>$ C mutation. No carriers of the p.Arg696Pro mutation were detected in this group of individuals (Rabbi J Ekstein, email communication, September, 2017). The presence of the IVS20+6T $>$ C mutation in individuals who identify themselves as being of pure Sephardic lineages likely reflects the incomplete genealogical knowledge of the participants and highlights the need to perform FD carrier testing on individuals who report themselves to be of pure Sephardic descent.

The ongoing FD genetic screening programs and the recommendation of the American College of Obstetricians and Gynecologists that carrier screening for FD be offered to couples of $\mathrm{AJ}$ descent ${ }^{29}$ has resulted in a dramatic decrease in the number of children born with this disorder. ${ }^{30}$

\section{The pleiotropic activities of the ELPI gene product}

The IKBKAP-encoded IKAP, originally named because of its purported role in the assembly of the IKB complex, ${ }^{31}$ was later determined to play no role in this pathway. ${ }^{32}$ IKAP was subsequently determined to be the Elongator protein 1 (ELP1) subunit of the highly conserved Elongator complex. ${ }^{33}$ The Elongator complex is detected in both the nucleus and cytoplasm. In the nucleus, the Elongator complex interacts with RNA polymerase II, playing a critical role in RNA polymerase II transcriptional activity and histone acetylation. ${ }^{33,34}$ In the cytoplasm, ELP1, either as a component of the Elongator complex or acting independently, is involved in diverse cellular functions, including cell migration and adhesion, ${ }^{35,36}$ intracellular trafficking, ${ }^{37}$ tRNA modification, ${ }^{38,39}$ cytoplasmic kinase signaling, ${ }^{40}$ and p53 activation. ${ }^{41}$ Whether these diverse biological activities represent distinct functions or are the result of a single biological activity that leads to various different downstream effects, remains to be determined. $^{42}$

\section{Monoamine oxidase deficiency in FD patients and the role it plays in the pathophysiology of the disease}

In the early 1960s, Smith and Dancis demonstrated that individuals with FD exhibit an exaggerated blood pressure response to systemic infusion of low doses of norepinephrine (NE) and proposed that this increased sensitivity plays a role in the symptomology of these patients. ${ }^{43}$ The dysregulated response of FD patients to catecholamines was further established in studies demonstrating: 1) an exaggerated hypotensive response to infusion with methacholine ${ }^{44} ; 2$ ) excessive miosis following instillation of methacholine drops into the conjunctival $\mathrm{sac}^{45}$; and 3) prolonged vasoconstriction in peripheral blood vessels following NE application. ${ }^{46}$ The elevated presence of NE and dopamine (DA) detected in the plasma of FD patients during hypertensive crises ${ }^{13,15}$ supports the proposed role of increased catecholamines in the precipitation of hypertensive crises. ${ }^{19}$

The observed elevated levels of catecholamines in the plasma of FD patients during hypertensive crises and the overlapping symptoms manifested in FD patients during a hypertensive crisis ${ }^{13}$ with those observed in individuals treated with monoamine oxidase inhibitors (MAOIs) who have ingested biogenic amines, ${ }^{47,48}$ prompted a study of the levels of the MAOs, key isoenzymes responsible for the degradation of biogenic and dietary monoamines, in FD-derived tissues and cells. ${ }^{17} \mathrm{~A}$ reduced presence of the $M A O-A$ encoding transcript and the MAO-A protein was observed in liver and kidney tissue samples from fetuses homozygous for the IVS20+6T $>C$ mutation and the $M A O-A$ encoding transcript was found to be reduced in peripheral blood cells of FD-affected individuals. No deficit in $M A O-B$ gene expression was detected in the FD-derived tissues/ cells. ${ }^{17}$ The reduced presence of the MAO-A gene product in individuals with FD, which would result in a prolonged circulating presence of various catecholamines, likely explains the exaggerated hypertensive response to infusion of low doses of $\mathrm{NE},{ }^{43}$ the altered pattern of catecholamine metabolites observed in the plasma of individuals with FD, ${ }^{49}$ the prolonged vasoconstriction in peripheral blood vessels following NE application, ${ }^{46}$ the onset of dysautonomic crisis following emotional events that trigger the release of $\mathrm{NE}$ and DA, ${ }^{13}$ the elevated circulating levels of $\mathrm{NE}$ and DA observed in the plasma of FD patients during hypertensive/ dysautonomic crises ${ }^{13,15}$ and the onset of hypertensive/dysautonomic crises following the ingestion of foods containing tyramine, ${ }^{17,18}$ a biogenic amine that also triggers hypertensive crises in individuals taking MAOIs.

The demonstrated MAO-A deficiency in FD patients has informed physicians of the need to avoid the use of serotonergic medications for these patients and has enabled anesthesiologists to select anesthetics and analgesics that do not precipitate the labile blood pressures and hypertensive crises that commonly occurred during and following anesthesia in these patients. ${ }^{50-53}$ 


\section{Treating FD: symptom-targeting therapies}

Pharmacological approaches currently used to treat FD patients have primarily focused on treating the symptoms manifested in these individuals. Hypertension and hypertensive/dysautonomic crises are typically treated with a combination of clonidine, a centrally acting $\alpha 2$ adrenergic agonist, and diazepam, a benzodiazepine. ${ }^{54}$ Hypotension is treated with fludrocortisone, a synthetic mineralocorticoid, which increases the blood volume and elevates blood pressure by increasing renal sodium and water reabsorption, ${ }^{55}$ and/ or midodrine, a peripherally acting $\alpha 1$-adrenergic agonist. ${ }^{56}$ Gastroesophageal reflux is treated with either histamine H2-receptor antagonists and/or proton pump inhibitors ${ }^{19}$ and insufficient tear production is treated with the administration of artificial tears. ${ }^{57}$ Many of the medications currently used to treat these patients are sedating and their ongoing use can severely compromise the quality of life of these patients. In addition, it has recently been reported that medications used to control FD-related symptoms may be responsible for the high incidence of sudden unexpected death during sleep observed in this patient population. ${ }^{58}$ An extensive overview of the medications currently used to treat the symptomology of FD has recently been published. ${ }^{19}$

\section{Treating FD: the search for gene- targeting therapies}

The absence of FD symptoms in carriers of the IVS20+6T $>C$ mutation that produces a reduced amount of the ELP1 gene product, due to the presence of only 1 non-mutated $E L P 1$ allele, clearly indicates that there is a threshold amount of the IKAP protein that is sufficient to enable normal neuronal development and survival. The observed ability of the IVS20+6T $>C$ bearing $E L P 1$ allele to produce some functional gene product in FD patients prompted the screening of chemical libraries for compounds capable of facilitating the production of the functional ELPI gene product that might be used to ameliorate or reverse the neuronal dysfunction observed in FD patients.

When considering the clinical use of compounds that alter gene expression or the RNA splicing process, it is important to consider the potential off-target toxic effects these compounds may have..$^{59,60} \mathrm{In}$ an effort to avoid or minimize potential off-target-mediated toxicities, Anderson et al screened a library of commonly ingested compounds for their impact on the expression of the correctly spliced ELP1 transcript and IKAP protein in FD-derived cells. In 2003, Anderson et al reported that tocotrienols, a form of vitamin $\mathrm{E}$ found in brown rice, and epigallocatechin gallate
(EGCG), a polyphenol present in green tea, increase expression of the correctly spliced ELP1 transcript in FD-derived cells by upregulating transcription of the ELPI gene ${ }^{61}$ and by altering the splicing of the ELP1 transcript. ${ }^{62}$

In 2004, kinetin (6-furfurylaminopurine), a plant cytokinin, was shown to facilitate the production of the exon 20-containing ELP1 transcript by altering the splicing process. $^{63}$

A full listing of the chemical compounds and other substances identified to date capable of increasing the production of the exon 20-containing (wild-type) ELP1 transcript in cells homozygous for the FD-causing IVS20+6T $>\mathrm{C}$ mutation is presented in Table 1.

\section{Treating FD: the in vivo response to gene-targeting therapies}

The first in vitro-identified gene-targeting agent clinically evaluated in FD patients was the tocotrienols. As tocotrienols are commonly ingested as a component of rice bran and no adverse side effects have been observed in humans at doses as high as $200 \mathrm{mg} /$ day, ${ }^{71,72}$ the risk of toxicity was considered minimal, and FD patients were enrolled in a study in which they ingested a daily dose of $100 \mathrm{mg}$ of tocotrienol for a period of up to 6 months. The tocotrienol treatment resulted in: 1) an increase in the production of the exon 20-containing ELP1 transcript and the MAO-A transcript in peripheral blood cells $;{ }^{17}$ ) a reduction in the frequency of hypertensive crises in excess of $82 \%$ of the participants enrolled in the study and a complete elimination of these crises in $40 \%$ of the study participants; ${ }^{73} 3$ ) an improved cardiac response to exercise $^{73}$; and 4) increased lacrimation. ${ }^{73-75}$

The results of a second clinical trial, which assessed the impact of tocotrienol ingestion on a cohort of $28 \mathrm{FD}$ patients, were recently published. ${ }^{76}$ The participants in this open label study ingested either 50 or $100 \mathrm{mg}$ of tocotrienols for an initial 3-month period and then either 100 or 200 $\mathrm{mg}$ of tocotrienols for a second 3-month period. This study demonstrated that tocotrienol mediated: 1) reduction in the number of pneumonias; 2) reduced sweating, blotching and dizziness; and 3) increased stability in walking. ${ }^{76}$ After 3 months of the tocotrienol therapy, a significant increase in the expression of the exon 20-containing ELP1 transcript was detected in peripheral blood cells of these patients. For reasons that are unclear, no increase in the exon 20-containing ELP1 transcript in the peripheral blood cells was detected at the 6-month time point.

The tocotrienol-mediated reduction in the frequency of pneumonias ${ }^{76}$ and hypertensive crises, ${ }^{73}$ which are the leading 
Table I Substances that increase levels of the exon 20-containing ELPI transcript

\begin{tabular}{|c|c|c|}
\hline Substance(s) & Impact on the ELPI transcript & Mechanism of action \\
\hline Tocotrienols ${ }^{61}$ & Increases transcription rate & Not determined \\
\hline EGCG 62 & Exon 20 inclusion & Downregulates hnRNP A2/BI \\
\hline Kinetin $^{63}$ & Exon 20 inclusion & Not determined \\
\hline Phosphatidylserine $e^{64,65}$ & Increases transcription rate & Activates MAPK/ERK signaling pathway \\
\hline Genistein/daidzein ${ }^{66}$ & Exon 20 inclusion & Not determined \\
\hline Genistein + EGCG 66 & Exon 20 inclusion & Not determined \\
\hline Cardiac glycosides ${ }^{67}$ & Exon 20 inclusion & Downregulate SRSF3 \\
\hline RECTAS $^{68}$ & Exon 20 inclusion & Not determined \\
\hline Proteasome inhibitors ${ }^{69}$ & Exon 20 inclusion & Not determined \\
\hline $\mathrm{RBM} 24^{70}$ & Exon 20 inclusion & Promotes UI snRNP recognition of mutated 5' splice site \\
\hline
\end{tabular}

Abbreviations: EGCG, epigallocatechin gallate; ERK, extracellular-signal-regulated kinase; hnRNP, heterogeneous nuclear ribonucleoproteins; MAPK, mitogen activated protein kinase; RBM24, RNA binding motif protein 24; RECTAS, RECTifier of aberrant splicing; snRNP, small nuclear ribonucleoproteins; SRSF3, serine/arginine-rich splicing factor 3 .

causes of death in FD patients, ${ }^{14,77}$ strongly support their continued administration. The tocotrienol-mediated increased tear production ${ }^{73-75}$ has helped FD patients avoid the recurrent corneal abrasions/ulcers that typically result from the lack of tear production. ${ }^{57}$ The observed tocotrienol-mediated increased stability in walking ${ }^{76}$ reduced sweating and blotching $^{76}$ and increased lacrimation ${ }^{73-75}$ suggest improvement in sympathetic and parasympathetic neuronal function. These findings demonstrate the in vivo impact of the tocotrienols and suggest that the long-term ingestion of the tocotrienols may preserve neuronal function and extend the life span of FD patients.

Additional clinical studies assessing the impact of tocotrienol administration on the FD patient population are needed and the recent report demonstrating the absence of any adverse side effects in humans at doses as high as 1,000 $\mathrm{mg} /$ day $^{78}$ suggests that the therapeutic impact of higher doses of the tocotrienols can be safely evaluated.

In light of the significant autonomic instability that occurs in FD patients during the perioperative period, ${ }^{52,53}$ Cook-Sather et al monitored the perioperative course in an FD patient receiving daily administration of $600 \mathrm{mg}$ of tocotrienols and $700 \mathrm{mg}$ of EGCG. ${ }^{51}$ The daily administration of these nutraceuticals was not interrupted in preparation of the surgery and the child received the normal dosing on the morning of the procedure. Other than a brief drop in arterial blood pressure that was observed during the induction of anesthesia with sevoflurane, no significant alterations in heart rate or arterial blood pressure were observed during the procedure. Following the surgical procedure, the patient's blood pressure remained stable, the patient did not experience any nausea or vomiting, and there was no evidence of any autonomic dysfunction. The authors noted that this perioperative course was very different than that experienced by this child during a previous surgery that was performed prior to the discovery of the functional IKAP-enhancing activity of the tocotrienols and EGCG. Following the previous procedure, the child experienced post-operative apnea, hypotension and severe refractory vomiting. Based on their findings, the authors strongly recommend the continued use of tocotrienol and green tea supplementation for FD patients undergoing surgery. ${ }^{51}$

Kinetin's ability to alter the splicing process and facilitate exon 20 inclusion in the ELPI transcript produced in FDderived cells prompted an examination of the impact of kinetin ingestion on carriers of the IVS20+6T $>C$ mutation. The kinetin ingestion, for an 8-day period, resulted in increased functional ELP1 mRNA expression in the peripheral blood cells of these test subjects. The most commonly reported side effect reported by the participants in the study was nausea. ${ }^{79}$ Based on these findings, kinetin was administered at a dose of $23.5 \mathrm{mg} / \mathrm{kg}$ for 28 days to $8 \mathrm{FD}$ patients homozygous for the IVS20+6T $>C$ allele. The average percentage of correctly spliced ELP1 mRNA present in the blood cells of these patients before kinetin ingestion was 54\%. After 8 and 28 days of kinetin ingestion, the percentage increased to $57 \%$ and $71 \%$, respectively. Blood tests performed on these patients revealed significant hepatotoxicity in 3 of the 8 patients in this cohort and 1 patient experienced a decrease in platelet and white blood cell counts. The kinetin administration did not improve the blood pressure, heart rate or neurological function in these patients. ${ }^{80}$

\section{The development of FD mouse models}

Recent scientific studies have challenged the validity of using mouse models to recapitulate a human disease phenotype and predict the responsiveness of humans to drug candidates. ${ }^{81,82}$ 
The use of mouse models to study compounds that alter the splicing process in human cells or transcriptionally upregulate genes of interest are further fraught with challenges, as the splicing process in humans and mice is very different ${ }^{83,84}$ and transcriptional regulation and promoter sequences have evolutionarily diverged in these species. ${ }^{85,86}$ Despite these potential pitfalls, investigators have endeavored to create a suitable FD mouse model in which to characterize the in vivo effects of chemical compounds demonstrated to increase the production of the exon 20-containing ELP1 transcript in cell lines ${ }^{61,63}$ and induced pluripotent stem cell-derived lineages ${ }^{87}$ generated from individuals homozygous for the FD-causing IVS20+6T $>$ C mutation. Attempts to generate an FD mouse model bearing the major FD-causing mutation in the conserved intron 20 donor splice site of the mouse ELP1 homolog, Ikbkap (current nomenclature as per the Mouse Genomic Nomenclature Committee), which would most closely model the human FD-causing mutation, failed. ${ }^{88,89}$ Using an alternative approach, Bochner and coworkers generated a knock-in humanized mouse model in which the human exon 20, with its flanking introns bearing the IVS20 $+6 \mathrm{~T}>\mathrm{C}$ mutation, replaced the corresponding mouse genomic sequence. ${ }^{89}$ This effort failed to generate a suitable FD mouse model, as the homozygous inheritance of this humanized allele generated animals that were fully viable and did not display any FD symptoms. ${ }^{89}$ The failure of both of these approaches to generate an FD mouse model clearly indicates that the regulation of splicing and the impact of the IVS20+6T $>C$ is very different in man and mouse. It is likely that the lack of identity in the exon and intron sequences of the human ELP1 and mouse Ikbkap genes and the differential expression of critical components of the splicing machinery in humans and mouse tissues ${ }^{90}$ play a role in this differential response. The inability to generate a mouse model homozygous for the major FD mutation that recapitulates the FD phenotype undermines the ability to perform preclinical testing in mice using chemical compounds found to enhance the production of the wild-type ELP1 transcript in FD-derived human cells.

To study the role IKAP plays in the development of the nervous system and in the pathophysiology of FD, investigators attempted to generate mice that were homozygous for either a disrupted murine Ikbkap gene (termed Ikbkap $\left.{ }^{-/}\right)^{91,92}$ or were homozygous for an exon 20-lacking murine Ikbkap gene (termed Ikbkap ${ }^{\Delta 20 / \Delta 20}$ ). ${ }^{92}$ The homozygous inheritance of these altered Ikbkap genes resulted in embryonic lethality. Morphological examination of these embryos revealed developmental delay, vascular and cardiovascular defects and neuronal malformations. Interestingly, the introduction of the normal human ELP1 transgene into the $\mathrm{Ikbkap}^{-/}$mice generated animals that were phenotypically normal while the introduction of a human ELPI transgene bearing the FD-causing mutation into these animals failed to rescue the embryonic lethality. ${ }^{91}$ These findings suggest that the level of expression of the correctly spliced transcript from the transgene bearing the FD-causing mutation was insufficient to enable the survival of these animals.

Two mouse models producing a reduced amount of the IKAP protein were successfully developed through the generation of: 1) animals homozygous for an altered murine Ikbkap allele bearing an insertion of loxP sites flanking exon 20 sequence of the Ikbkap gene (termed Ikbkap flox/flox), which exhibited a $90 \%$ reduction in IKAP protein expression, and 2) animals heterozygous for the loxP site-containing Ikbkap murine gene and an exon 20-lacking murine Ikbkap allele (termed Ikbkap ${ }^{\Delta 20 / f l o x}$ ), which exhibited a 95\% reduction in functional IKAP expression. ${ }^{88}$ Histological studies of the superior cervical ganglia, the dorsal root ganglia and epidermal innervation in these mice reveal that they recapitulate the neuronal deficits seen in individuals with FD. These mouse models also exhibit the unsteady gait, poor motor coordination, postural instability, gastrointestinal dysfunction, reduced number of fungiform papillae on the tongue, skeletal abnormalities and the reduced lifespan observed in FD patients. These animals also display the reduced expression of genes involved in oligodendrocyte maturation and myelin formation that is observed in the brains of FD patients. ${ }^{93}$ The FD-like phenotype and the neuronal deficits in the Ikbkap floxflox mouse model, which produce $\sim 10 \%$ of the wild-type levels of the IKAP protein, were significantly milder than those observed in the Ikbkap ${ }^{\Delta 20 / f l o x}$ mouse model, which produce $\sim 5 \%$ of the wild-type levels of the IKAP protein. Furthermore, the Ikbkap ${ }^{\text {floxfflox }}$ mice had a longer lifespan than the Ikbkap ${ }^{\Delta 20 / f l o x}$ mice. These findings support the hypothesis that therapeutic modalities that generate even slight increases in wild-type ELP1 (IKAP) levels in FD patients may greatly ameliorate the severity of this disease.

The absence of the disease-causing IVS20+6T $>$ C mutation in these animals, which precluded their use as a model to study the clinical and molecular impact of the in vitro identified splice-altering and ELP 1 transcription-upregulating compounds, prompted the introduction of the complete human ELP1 transgene bearing the IVS20+6T $>$ C mutation into the $I k b k a p^{\Delta 20 / \text { flox }}$ mice. The resulting animals exhibit many of the features of the FD phenotype and the splicing of the human ELP1 transcript in these animals displays 
the same tissue-specific splicing observed in FD patients. Kinetin ingestion by these animals facilitates the inclusion of the exon 20 sequence in the ELP1 transcript produced by the human IVS20+6T $>C$ bearing allele. ${ }^{94}$ The impact of the kinetin treatment on the FD phenotype of these animals has not yet been reported.

\section{Conclusion}

The discovery of the splice-altering nature of the mutation in the ELPl (IKBKAP) gene that causes FD has rapidly led to an increased understanding of: 1) the pathophysiology of this disorder; 2) the role this gene plays in neuronal development and survival; and 3) the identification and utilization of novel therapeutics that facilitate the production of the correctly spliced gene product. As approximately one-third of disease-causing alleles are predicted to impact the splicing process, ${ }^{95}$ the successes achieved in identifying potential therapies for individuals with FD should serve as a model to address the pathogenicity of other splice-altering mutations. While genetic screening efforts are successfully reducing the numbers of children born with $\mathrm{FD},{ }^{30}$ the recent scientific progress made will likely result in the improved health and the prolonged survival of the current FD population.

\section{Acknowledgments}

This work was funded by grants from Familial Dysautonomia Now and the Eric Alterman Foundation for FD Cure.

\section{Disclosure}

The authors report no conflicts of interest in this work.

\section{References}

1. Riley CM, Day RL, Greeley DM, Langford WS. Central autonomic dysfunction with defective lacrimation; report of five cases. Pediatrics. 1949;3(4):468-478.

2. Axelrod FB, Nachtigal R, Dancis J. Familial dysautonomia: diagnosis, pathogenesis and management. Adv Pediatr. 1974;21:75-96.

3. Mendoza-Santiesteban CE, Hedges TR 3rd, Norcliffe-Kaufmann L, et al. Clinical neuro-ophthalmic findings in familial dysautonomia. J Neuroophthalmol. 2012;32(1):23-26.

4. Gutiérrez JV, Norcliffe-Kaufmann L, Kaufmann H. Brainstem reflexes in patients with familial dysautonomia. Clin Neurophysiol. 2015;126(3):626-633.

5. Aguayo AJ, Nair CP, Bray GM. Peripheral nerve abnormalities in the Riley-Day syndrome. Findings in a sural nerve biopsy. Arch Neurol. 1971;24(2):106-116.

6. Pearson J, Dancis J, Axelrod F, Grover N. The sural nerve in familial dysautonomia. J Neuropathol Exp Neurol. 1975;34(5):413-424.

7. Pearson J, Pytel BA, Grover-Johnson N, Axelrod F, Dancis J. Quantitative studies of dorsal root ganglia and neuropathologic observations on spinal cords in familial dysautonomia. J Neurol Sci. 1978;35(1):77-92.

8. Pearson J, Pytel BA. Quantitative studies of sympathetic ganglia and spinal cord intermedio-lateral gray columns in familial dysautonomia. J Neurol Sci. 1978;39(1):47-59.
9. Hilz MJ, Axelrod FB, Bickel A, et al. Assessing function and pathology in familial dysautonomia: assessment of temperature perception, sweating and cutaneous innervation. Brain. 2004;127(Pt 9):2090-2098.

10. Goldstein DS, Eldadah B, Sharabi Y, Axelrod FB. Cardiac sympathetic hypo-innervation in familial dysautonomia. Clin Auton Res. 2008;18(3):115-119.

11. Grover-Johnson N, Pearson J. Deficient vascular innervation in familial dysautonomia, an explanation for vasomotor instability. Neuropathol Appl Neurobiol. 1976;2(3):217-224.

12. Mendoza-Santiesteban CE, Palma JA, Hedges TR 3rd, et al. Pathological confirmation of optic neuropathy in familial dysautonomia. J Neuropathol Exp Neurol. 2017;76(3):238-244.

13. Axelrod FB. Familial dysautonomia. Muscle Nerve. 2004;29(3):352-363

14. Axelrod FB, Goldberg JD, Ye XY, Maayan C. Survival in familial dysautonomia: impact of early intervention. J Pediatr. 2002;141(4):518-523.

15. Norcliffe-Kaufmann LJ, Axelrod FB, Kaufmann H. Cyclic vomiting associated with excessive dopamine in Riley-day syndrome. J Clin Gastroenterol. 2013;47(2):136-138.

16. Axelrod FB. Hereditary sensory and autonomic neuropathies. Familial dysautonomia and other HSANs. Clin Auton Res. 2002;12(Suppl 1): $12-14$.

17. Anderson SL, Rubin BY. Tocotrienols reverse IKAP and monoamine oxidase deficiencies in familial dysautonomia. Biochem Biophys Res Commun. 2005;336(1):150-156.

18. Rubin BY, Anderson SL. The molecular basis of familial dysautonomia: overview, new discoveries and implications for directed therapies. Neuromolecular Med. 2008;10(3):148-156.

19. Palma JA, Norcliffe-Kaufmann L, Fuente-Mora C, Percival L, MendozaSantiesteban C, Kaufmann H. Current treatments in familial dysautonomia. Expert Opin Pharmacother. 2014;15(18):2653-2671.

20. Anderson SL, Coli R, Daly IW, et al. Familial dysautonomia is caused by mutations of the IKAP gene. Am J Hum Genet. 2001;68(3):753-758.

21. Slaugenhaupt SA, Blumenfeld A, Gill SP, et al. Tissue-specific expression of a splicing mutation in the IKBKAP gene causes familial dysautonomia. Am J Hum Genet. 2001;68(3):598-605.

22. Carmel I, Tal S, Vig I, Ast G. Comparative analysis detects dependencies among the 5' splice-site positions. RNA. 2004;10(5):828-840.

23. Leyne M, Mull J, Gill SP, et al. Identification of the first non-Jewish mutation in familial Dysautonomia. Am JMed Genet A. 2003;118A(4) 305-308.

24. Maayan C, Kaplan E, Shachar S, Peleg O, Godfrey S. Incidence of familial dysautonomia in Israel 1977-1981. Clin Genet. 1987;32(2):106-108.

25. Fares F, Badarneh K, Abosaleh M, Harari-Shaham A, Diukman R, David M. Carrier frequency of autosomal-recessive disorders in the Ashkenazi Jewish population: should the rationale for mutation choice for screening be reevaluated? Prenat Diagn. 2008;28(3):236-241.

26. Lehavi O, Aizenstein O, Bercovich D, et al. Screening for familial dysautonomia in Israel: evidence for higher carrier rate among Polish Ashkenazi Jews. Genet Test. 2003;7(2):139-142.

27. Ekstein J, Katzenstein H. The Dor Yeshorim story: community-based carrier screening for Tay-Sachs disease. Adv Genet. 2001;44:297-310.

28. Brunt PW, McKusick VA. Familial dysautonomia. A report of genetic and clinical studies, with a review of the literature. Medicine (Baltimore). 1970;49(5):343-374.

29. ACOG Committee on Genetics. ACOG committee opinion. Number 298, August 2004. Prenatal and preconceptional carrier screening for genetic diseases in individuals of Eastern European Jewish descent. Obstet Gynecol. 2004;104(2):425-428.

30. Lerner BH. When diseases disappear--the case of familial dysautonomia. N Engl J Med. 2009;361(17):1622-1625.

31. Cohen L, Henzel WJ, Baeuerle PA. IKAP is a scaffold protein of the IkappaB kinase complex. Nature. 1998;395(6699):292-296.

32. Krappmann D, Hatada EN, Tegethoff S, et al. The I kappa B kinase (IKK) complex is tripartite and contains IKK gamma but not IKAP as a regular component. J Biol Chem. 2000;275(38):29779-29787.

33. Hawkes NA, Otero G, Winkler GS, et al. Purification and characterization of the human elongator complex. J Biol Chem. 2002;277(4):3047-3052. 
34. Kim JH, Lane WS, Reinberg D. Human Elongator facilitates RNA polymerase II transcription through chromatin. Proc Natl Acad Sci US A. 2002;99(3):1241-1246.

35. Johansen LD, Naumanen T, Knudsen A, et al. IKAP localizes to membrane ruffles with filamin A and regulates actin cytoskeleton organization and cell migration. $J$ Cell Sci. 2008;121(Pt 6):854-864.

36. Creppe C, Malinouskaya L, Volvert ML, et al. Elongator controls the migration and differentiation of cortical neurons through acetylation of alpha-tubulin. Cell. 2009;136(3):551-564.

37. Rahl PB, Chen CZ, Collins RN. Elp1p, the yeast homolog of the FD disease syndrome protein, negatively regulates exocytosis independently of transcriptional elongation. Mol Cell. 2005;17(6):841-853.

38. Lin FJ, Shen L, Jang CW, Falnes PØ, Zhang Y. Ikbkap/Elp1 deficiency causes male infertility by disrupting meiotic progression. PLoS Genet. 2013;9(5):e1003516.

39. Karlsborn T, Tükenmez H, Mahmud AK, Xu F, Xu H, Byström AS. Elongator, a conserved complex required for wobble uridine modifications in eukaryotes. RNA Biol. 2014;11(12):1519-1528.

40. Holmberg C, Katz S, Lerdrup M, et al. A novel specific role for I kappa B kinase complex-associated protein in cytosolic stress signaling. J Biol Chem. 2002;277(35):31918-31928.

41. Cornez I, Creppe C, Gillard M, et al. Deregulated expression of pro-survival and pro-apoptotic p53-dependent genes upon Elongator deficiency in colon cancer cells. Biochem Pharmacol. 2008;75(11): 2122-2134.

42. Svejstrup JQ. Elongator complex: how many roles does it play? Curr Opin Cell Biol. 2007;(3):331-336.

43. Smith AA, Dancis J. Exaggerated response to infused norepinephrine in familial dysautonomia. N Engl J Med. 1964;270(14):704-707.

44. Smith AA, Hirsch JI, Dancis J. Responses to infused methacholine in familial dysautonomia. Pediatrics. 1965;36(2):225-230.

45. Smith AA, Dancis J, Breinin G. Ocular responses to autonomic drugs in familial dysautonomia. Invest Ophthalmol. 1965;4(3):358-361.

46. Bickel A, Axelrod FB, Schmelz M, Marthol H, Hilz MJ. Dermal microdialysis provides evidence for hypersensitivity to noradrenaline in patients with familial dysautonomia. J Neurol Neurosurg Psychiatry. 2002;73(3):299-302.

47. Blackwell B. Hypertensive crisis due to monoamine-oxidase inhibitors. Lancet. 1963;2(7313):849-850.

48. Blackwell B, Marley E, Ryle A. Hypertensive crisis associated with monoamine-oxidase inhibitors. Lancet. 1964;1(7335):722-723.

49. Axelrod FB, Goldstein DS, Holmes C, Berlin D, Kopin IJ. Pattern of plasma levels of catecholamines in familial dysautonomia. Clin Auton Res. 1996;6(4):205-209.

50. Abulhasan Y, Buu N, Frigon C. Perioperative use of dexmedetomidine in an infant with familial dysautonomia. $\mathrm{Br} J$ Anaesth. 2009;103(3):413-415.

51. Cook-Sather SD, Viola L, Zur KB, Rubin BY. Case scenario: perioperative administration of tocotrienols and green tea extract in a child with familial dysautonomia. Anesthesiology. 2012;117(3):639-645.

52. Ngai J, Kreynin I, Kim JT, Axelrod FB. Anesthesia management of familial dysautonomia. Paediatr Anaesth. 2006;16(6):611-620.

53. Weingarten TN, Sprung J, Burgher AH. Perioperative management of familial dysautonomia: a systematic review. Eur J Anaesthesiol. 2007;24(4):309-316.

54. Axelrod FB. Familial dysautonomia: a review of the current pharmacological treatments. Expert Opin Pharmacother. 2005;6(4):561-567.

55. Axelrod FB, Goldberg JD, Rolnitzky L, et al. Fludrocortisone in patients with familial dysautonomia-assessing effect on clinical parameters and gene expression. Clin Auton Res. 2005;15(4):284-291.

56. Axelrod FB, Krey L, Glickstein JS, Allison JW, Friedman D. Preliminary observations on the use of midodrine in treating orthostatic hypotension in familial dysautonomia. J Auton Nerv Syst. 1995;55(1-2):29-35.

57. Goldberg MF, Payne JW, Brunt PW. Ophthalmologic studies of familial dysautonomia. The Riley-Day syndrome. Arch Ophthalmol. 1968;80(6):732-743.
58. Palma JA, Norcliffe-Kaufmann L, Perez MA, Spalink CL, Kaufmann $\mathrm{H}$. Sudden unexpected death during sleep in familial dysautonomia: a case-control study. Sleep. 2017;40(8).

59. Ohe K, Hagiwara M. Modulation of alternative splicing with chemical compounds in new therapeutics for human diseases. ACS Chem Biol. 2015;10(4):914-924.

60. Bates DO, Morris JC, Oltean S, Donaldson LF. Pharmacology of modulators of alternative splicing. Pharmacol Rev. 2017;69(1):63-79.

61. Anderson SL, Qiu J, Rubin BY. Tocotrienols induce IKBKAP expression: a possible therapy for familial dysautonomia. Biochem Biophys Res Commun. 2003;306(1):303-309.

62. Anderson SL, Qiu J, Rubin BY. EGCG corrects aberrant splicing of IKAP mRNA in cells from patients with familial dysautonomia. Biochem Biophys Res Commun. 2003;310(2):627-633.

63. Slaugenhaupt SA, Mull J, Leyne M, et al. Rescue of a human mRNA splicing defect by the plant cytokinin kinetin. Hum Mol Genet. 2004;13(4):429-436.

64. Keren H, Donyo M, Zeevi D, Maayan C, Pupko T, Ast G. Phosphatidylserine increases IKBKAP levels in familial dysautonomia cells. PLoS One. 2010;5(12):e15884

65. Donyo M, Hollander D, Abramovitch Z, Naftelberg S, Ast G. Phosphatidylserine enhances IKBKAP transcription by activating the MAPK/ ERK signaling pathway. Hum Mol Genet. 2016;25(7):1307-1317.

66. Anderson SL, Liu B, Qiu J, et al. Nutraceutical-mediated restoration of wild-type levels of IKBKAP-encoded IKAP protein in familial dysautonomia-derived cells. Mol Nutr Food Res. 2012;56(4):570-579.

67. Liu B, Anderson SL, Qiu J, Rubin BY. Cardiac glycosides correct aberrant splicing of IKBKAP-encoded mRNA in familial dysautonomia derived cells by suppressing expression of SRSF3. FEBS $J$. 2013;280(15):3632-3646.

68. Yoshida M, Kataoka N, Miyauchi K, et al. Rectifier of aberrant mRNA splicing recovers tRNA modification in familial dysautonomia. Proc Natl Acad Sci U S A. 2015;112(9):2764-2769.

69. Hervé M, Ibrahim EC. Proteasome inhibitors to alleviate aberrant IKBKAP mRNA splicing and low IKAP/hELP1 synthesis in familial dysautonomia. Neurobiol Dis. 2017;103:113-122.

70. Ohe K, Yoshida M, Nakano-Kobayashi A, et al. RBM24 promotes U1 snRNP recognition of the mutated 5' splice site in the IKBKAP gene of familial dysautonomia. RNA. 2017;23(9):1393-1403.

71. Qureshi AA, Qureshi N, Wright JJ, et al. Lowering of serum cholesterol in hypercholesterolemic humans by tocotrienols (palmvitee). Am J Clin Nutr. 1991;53(4 Suppl):1021S-1026S.

72. Qureshi AA, Bradlow BA, Brace L, et al. Response of hypercholesterolemic subjects to administration of tocotrienols. Lipids. 1995;30(12):1171-1177.

73. Rubin BY, Anderson SL, Kapás L. Can the therapeutic efficacy of tocotrienols in neurodegenerative familial dysautonomia patients be measured clinically? Antioxid Redox Signal. 2008;10(4):837-841.

74. Gold-von Simson G, Axelrod FB. Familial dysautonomia: update and recent advances. Curr Probl Pediatr Adolesc Health Care. 2006;36(6):218-237.

75. D'Amico RA. Familial dysautonomia; 2016. Available from: http:// emedicine.medscape.com/article/1200921-overview. Accessed August 30, 2017.

76. Cheishvili D, Maayan C, Holzer N, et al. Tocotrienol treatment in familial dysautonomia: open-label pilot study. $J$ Mol Neurosci. 2016;59(3):382-391.

77. Axelrod FB, Rolnitzky L, Gold von Simson G, Berlin D, Kaufmann H. A rating scale for the functional assessment of patients with familial dysautonomia (Riley Day syndrome). J Pediatr. 2012;161(6):1160-1165.

78. Qureshi AA, Khan DA, Silswal N, Saleem S, Qureshi. Evaluation of pharmacokinetics, and bioavailability of higher doses of tocotrienols in healthy fed humans. J Clin Exp Cardiolog. 2016;7(4):434.

79. Gold-von Simson G, Goldberg JD, Rolnitzky LM, et al. Kinetin in familial dysautonomia carriers: implications for a new therapeutic strategy targeting mRNA splicing. Pediatr Res. 2009;65(3):341-346. 
80. Axelrod FB, Liebes L, Gold-Von Simson G, et al. Kinetin improves IKBKAP mRNA splicing in patients with familial dysautonomia. Pediatr Res. 2011;70(5):480-483.

81. Seok J, Warren HS, Cuenca AG, et al. Genomic responses in mouse models poorly mimic human inflammatory diseases. Proc Natl Acad Sci USA. 2013;110(9):3507-3512.

82. Akhtar A. The flaws and human harms of animal experimentation. Camb $Q$ Healthc Ethics. 2015;24(4):407-419.

83. Pan Q, Bakowski MA, Morris Q, et al. Alternative splicing of conserved exons is frequently species-specific in human and mouse. Trends Genet. 2005;21(2):73-77.

84. Barbosa-Morais NL, Irimia M, Pan Q, etal. The evolutionary landscape of alternative splicing in vertebrate species. Science. 2012;338(6114):1587-1593.

85. Odom DT, Dowell RD, Jacobsen ES, et al. Tissue-specific transcriptional regulation has diverged significantly between human and mouse. Nat Genet. 2007;39(6):730-732.

86. Young RS, Hayashizaki Y, Andersson R, et al. The frequent evolutionary birth and death of functional promoters in mouse and human. Genome Res. 2015;25(10):1546-1557.

87. Lee G, Papapetrou EP, Kim H, et al. Modelling pathogenesis and treatment of familial dysautonomia using patient-specific iPSCs. Nature. 2009;461(7262):402-406.

88. Dietrich P, Alli S, Shanmugasundaram R, Dragatsis I. IKAP expression levels modulate disease severity in a mouse model of familial dysautonomia. Hum Mol Genet. 2012;21(23):5078-5090.
89. Bochner R, Ziv Y, Zeevi D, et al. Phosphatidylserine increases IKBKAP levels in a humanized knock-in IKBKAP mouse model. Hum Mol Genet. 2013;22(14):2785-2794.

90. Grosso AR, Gomes AQ, Barbosa-Morais NL, et al. Tissue-specific splicing factor gene expression signatures. Nucleic Acids Res. 2008;36(15):4823-4832.

91. Chen YT, Hims MM, Shetty RS, et al. Loss of mouse Ikbkap, a subunit of elongator, leads to transcriptional deficits and embryonic lethality that can be rescued by human IKBKAP. Mol Cell Biol. 2009;29(3): 736-744.

92. Dietrich P, Yue J, Shuyu E, Dragatsis I. Deletion of exon 20 of the Familial Dysautonomia gene Ikbkap in mice causes developmental delay, cardiovascular defects, and early embryonic lethality. PLoS One. 2011;6(10):e27015.

93. Cheishvili D, Dietrich P, Maayan C, et al. IKAP deficiency in an FD mouse model and in oligodendrocyte precursor cells results in downregulation of genes involved in oligodendrocyte differentiation and myelin formation. PLoS One. 2014;9(4):e94612.

94. Morini E, Dietrich P, Salani M, et al. Sensory and autonomic deficits in a new humanized mouse model of familial dysautonomia. Hum Mol Genet. 2016;25(6):1116-1128.

95. Daguenet E, Dujardin G, Valcárcel J. The pathogenicity of splicing defects: mechanistic insights into pre-mRNA processing inform novel therapeutic approaches. EMBO Rep. 2015;16(12):1640-1655.
The Application of Clinical Genetics

\section{Publish your work in this journal}

The Application of Clinical Genetics is an international, peer-reviewed open access journal that welcomes laboratory and clinical findings in the field of human genetics. Specific topics include: Population genetics; Functional genetics; Natural history of genetic disease; Management of genetic disease; Mechanisms of genetic disease; Counselling and ethical

\section{Dovepress}

issues; Animal models; Pharmacogenetics; Prenatal diagnosis; Dysmorphology. The manuscript management system is completely online and includes a very quick and fair peer-review system, which is all easy to use. Visit http://www.dovepress.com/testimonials.php to read real quotes from published authors. 